\title{
Micturition pattern in young boys with posterior urethral valves-A pilot study in small boys who are potty-trained from infancy
}

\author{
Thi Hoa Duong ${ }^{1,2,3}$, Gundela Holmdahl ${ }^{4}$, Duy Viet Nguyen ${ }^{2}$, Ulla Sillén ${ }^{4}$, Ulla-Britt Jansson ${ }^{4}$, \\ Anna-Lena Hellström ${ }^{1,3,4}$ \\ ${ }^{1}$ Institute of Health and Care Sciences, Sahlgrenska Academy at the University of Gothenburg, Gothenburg, Sweden \\ ${ }^{2}$ National Hospital of Pediatrics, Hanoi, Vietnam \\ ${ }^{3}$ Centre for Person-Centred Care (GPCC), University of Gothenburg, Gothenburg, Sweden \\ ${ }^{4}$ Queen Silvia Children's Hospital, Gothenburg, Sweden \\ Email: hoadt_nhp@yahoo.com, gundela.holmdahl@vgregion.se, vietnhi10@yahoo.com.vn, ulla.sillen@vgregion.se, \\ ullabritt.jansson@,vgregion.se, annalena.hellstrom@,fhs.gu.se
}

Received 5 October 2013; revised 9 November 2013; accepted 16 November 2013

Copyright (C) 2013 Thi Hoa Duong et al. This is an open access article distributed under the Creative Commons Attribution License, which permits unrestricted use, distribution, and reproduction in any medium, provided the original work is properly cited.

\begin{abstract}
Introduction: To investigate if potty training from infancy can affect bladder dysfunction in boys with posterior urethral valves (PUV). Subjects and Methods: The voiding pattern and emptying ability were followed using the 4-hour voiding observation method in 17 Vietnamese boys with PUV aged 3 months to 4 years who had been potty-trained from infancy. This group was compared with a group of healthy Vietnamese boys. Results: In the boys with PUV, the bladder volume increased according to age, and interrupted voiding was rare. However, when comparing boys with PUV with healthy boys, a significant difference was noted with more frequent voidings and lower voided volumes in the age group 0 - 1 year $(P<$ 0.001). Despite the minimum amount of residual urine, average $8 \mathrm{ml}$ or less in the boys with PUV, the age groups $1-2$ and $2-4$ years had significantly higher residual volumes compared with those of the healthy boys $(P<\mathbf{0 . 0 0 1})$. Conclusion: The findings from the 4-hour voiding observation showed few signs of dysfunctional bladder in the Vietnamese boys with PUV, including residual urine, even if there were signs of dysfunction compared with the healthy Vietnamese boys. Potty training from infancy could favor early bladder rehabilitation in boys with PUV.
\end{abstract}

Keywords: Bladder; Posterior Urethra Valves; Urination; Bladder Dysfunction; Children; Signs

\section{INTRODUCTION}

In boys with posterior urethral valves (PUV), bladder dysfunction is probably established already during fetal life as a response to a urethral obstruction [1]. It is estimated that this bladder dysfunction will persist in $75 \%$ of boys with PUV, and it could be a risk factor for the renal deterioration seen in long-term follow-ups [2-4].

Even if bladder dysfunction due to valves can show different patterns [5] in response to the grade of detrusor hypertrophy induced by the obstruction, it has been suggested that the pattern in infancy and first years of life is characterized by hyper-contractility. This is recognized as over-activity during filling with frequent voidings and low bladder capacity [6]. Another characteristic is incomplete emptying, which is mainly due to dyscoordination between the detrusor and sphincter at voiding. Later on during childhood and adolescence, an under-contractile detrusor can develop and cause emptying problems. A polyuria, due to obstructive uropathy with a low ability to concentrate urine, can further enhance the bladder dysfunction.

Previous studies have shown that in healthy children, with no history of urinary tract problems, the bladder function physiology changes when bladder control is achieved. One of the important changes is the advent of complete emptying, which is probably due to the disappearance of the physiological dyscoordination, which is seen as interrupted voiding [7]. Vietnamese children who are potty-trained already from infancy provide an opportunity to study the impact of early potty training on bladder function. The published data show that it is possible to start potty training with good outcomes very early in life $[8,9]$. With daily potty training, the children were able to empty their bladders completely already at 
the age of 9 months [8]. These findings suggest that potty training may be beneficial in young children with a high risk of urinary tract infection (UTI) or renal deterioration due to bladder emptying difficulties [10]. The aim of this pilot study was to investigate if potty training from infancy could affect the early bladder dysfunction seen in boys with PUV.

\section{PARTICIPANT AND METHODS}

Boys aged $0-4$ years with posterior urethral valves (PUV) were recruited consecutively from the National Hospital of Pediatrics (NHP) in Hanoi between February 2011 and April 2013, directly after the resection of valves or when they were readmitted due to urinary tract symptoms after earlier valve resection. Informed consent was obtained from the parents and the regional Ethic committee for research approved the study. In Vietnam, there is no structured follow-up after valve resection or tradition of prenatal ultrasound for detecting uropathies. Table 1 shows the age for resection and age at inclusion. Of the seventeen boys included, with verified valves diagnosed by voiding cystourethrography (VCU), five boys $(29 \%)$ had vesico-ureteral reflux grade 3 or more. Dilatation of the upper urinary tracts diagnosed by renal ultrasonography was seen in nine boys (53\%). The renal function, estimated by serum-creatinine, varied in the group of boys with PUV (Table 1). They had all been potty-trained from infancy according to Vietnamese culture, see below. From the age of 3 months, they were able to start a micturition at will, according to the mothers' reports. No patients were on anticholinergic or alpha-blocker medication.

Twenty-six healthy Vietnamese boys were followed with non-invasive bladder function studies longitudinally from the age of 3 months to 3 years and used as a control group [8]. The mother started the potty training already when the child was a newborn by learning to communicate the need and by prompting the child during infancy to urinate at $1-2$ hour intervals and $1-2$ times at night [9]. The parents used to prompt their children at certain times using a whistle sound. Daily potty training was applied to $98 \%$ of healthy Vietnamese children at the age of 12 months [8].

\subsection{Design}

The non-invasive 4-hour voiding observation method was used to study bladder function. Facilities for flow measurements were not available. The study participants were included at resection or when the patient was readmitted, as described above. The date of the 4-hour voiding observation was set within 3 months of inclusion. A follow-up was performed after 18 months. The data were reported according to age group: $0-1,1-2$, and $2-4$
Table 1. Age at inclusion and resection in the boys with PUV. Background data at time of inclusion and at $12-18$ month follow-ups.

\begin{tabular}{|c|c|}
\hline & $\mathbf{N}=17$ \\
\hline \multicolumn{2}{|l|}{ Age at inclusion in months, } \\
\hline Mean (SD) & $13(9.6)$ \\
\hline Median (min-max) & $17(3-54)$ \\
\hline \multicolumn{2}{|l|}{ Age at resection in months } \\
\hline Mean (SD) & $10(10.2)$ \\
\hline Median (min-max) & $3(3-36)$ \\
\hline \multicolumn{2}{|l|}{ Creatinine $/ \mathrm{s} \mu \mathrm{mol} / \mathrm{l}$, at inclusion } \\
\hline Mean (SD) & $68(44.4)$ \\
\hline Median (min-max) & $44(34-330)$ \\
\hline \multirow[t]{2}{*}{ At follow up } & $42(19.1)$ \\
\hline & $53(30-178)$ \\
\hline Dilatation at inclusion, n(\%) & $9(53)$ \\
\hline At follow up, n(\%) & $7(41)$ \\
\hline Dilated reflux at inclusion, n(\%) & $5(29)$ \\
\hline At follow up, n(\%) & $1(6)$ \\
\hline
\end{tabular}

${ }^{*}$ Ten boys were included close to resection, 7 within 4 years. The first 4-hour-voiding was performed within 3 months after inclusion.

years (Table 2). Furthermore, the findings were compared, by age group, with those of the healthy boys. When compared with the healthy group, they followed longitudinally; a patient can be present in two groups due to the 18-month follow-up, depending on the age of inclusion (Table 3).

Original data were available for the healthy boys used for the comparison [8].

\subsection{4-Hour Voiding Observation}

The 4-hour voiding observation method has been validated in previous studies [7,11]. Observation over a 4-hour period may enable a valid investigation, compared with a single sample. The child becomes used to the situation and can play, eat, and sleep when the child/parent wants. In the group of boys with PUV, all voided in a bottle or potty, often prompted by their parents. The urine was weighed and the post-void residual urine estimated by ultrasonography following each voiding, according to the original method [12]. The voided volumes and residual urine were measured in $\mathrm{ml}$ or $\mathrm{mg}$. The recordings were made every ten minutes, but the child had to be under constant observation throughout this period. Post-void residual urine was estimated by considering the bladder as a rectangular box and all three 
Table 2. 4-hour voiding observation in Vietnamese boys with PUV according to age. Values are shown for group at inclusion and 18 months after inclusion.

\begin{tabular}{|c|c|c|c|c|c|c|}
\hline \multirow[t]{4}{*}{ Ages } & \multicolumn{2}{|c|}{0 - 1 year $(n=8)$} & \multicolumn{2}{|c|}{1 - 2 years $(n=6)$} & \multicolumn{2}{|c|}{$2-4$ years $(n=3)$} \\
\hline & Inclusion & After 18 m & Inclusion & After $18 \mathrm{~m}$ & Inclusion & After $18 \mathrm{~m}$ \\
\hline & Mean (SD) & Mean (SD) & Mean (SD) & Mean (SD) & Mean (SD) & Mean (SD) \\
\hline & Md (min - max) & Md (min - max) & Md (min - max) & Md (min - max) & Md (min - max) & Md (min - max) \\
\hline \multirow{2}{*}{$\begin{array}{l}\text { Highest bladder } \\
\text { volume (ml) }\end{array}$} & $26(9)$ & $86(70)$ & $47(15)$ & $78(35)$ & $66(16)$ & $109(71)$ \\
\hline & $26(16-45)$ & $57(25-200)$ & $40(36-77)$ & $66(48-146)$ & $67(49-81)$ & $80(58-190)$ \\
\hline \multirow{2}{*}{$\begin{array}{l}\text { Number } \\
\text { of voiding }\end{array}$} & $4(2)$ & $5(1)$ & $5(2)$ & $3(1)$ & $5(2)$ & $3(1)$ \\
\hline & $4(2-6)$ & $5(3-6)$ & $5(3-7)$ & $4(2-4)$ & $5(3-6)$ & $3(2-3)$ \\
\hline \multirow{2}{*}{$\begin{array}{l}\text { Average residual } \\
\text { urine }(\mathrm{ml})\end{array}$} & $3(2)$ & $2(2)$ & $2(2)$ & $1(1)$ & $5(3)$ & $1(1)$ \\
\hline & $2(0-8)$ & $2(0-4)$ & $3(0-5)$ & $0(0-3)$ & $4(3-8)$ & $2(0-2)$ \\
\hline \multirow{2}{*}{$\begin{array}{l}\text { Lowest residual } \\
\text { urine }(\mathrm{ml})\end{array}$} & $2(2)$ & $1(1)$ & $0.5(1)$ & $0(0)$ & $2(2)$ & $0(0)$ \\
\hline & $1(0-6)$ & $0(0-3)$ & $0(0-2)$ & $0(0-0)$ & $3(0-4)$ & $0(0-0)$ \\
\hline
\end{tabular}

dimensions as variables: the width, height, and depth were multiplied to obtain the actual bladder volume [12]. Interrupted voiding was defined as more than one voiding within a period of 10 minutes and leaving a lower amount of residual urine after the last portion. The interrupted voiding is regarded as a sign of dyscoordination. The 4-hour voiding observation form was used for the registration of data. This procedure was also followed in the group of healthy boys whose data were used for comparison [8].

\subsection{Statistical Methods}

For comparisons between the PUV group and the healthy group of boys, the Mann-Whitney U-test was used for continuous variables and Fisher's exact test for dichotomous variables. For the comparisons of changes within the groups, the Wilcoxon Signed rank test was used.

In order to compare the groups at different age intervals, we used the value closest to the middle of the age interval for each child. All significance tests were twosided and conducted at the 5\% significance level. The distribution of continuous variables was given as mean, $\mathrm{SD}$, median, minimum, and maximum, and the distribution of categorical variables was given as a number and a percentage.

\section{RESULTS/FINDINGS}

None of the parents of the 17 recruited Vietnamese boys with PUV declined participation and all fulfilled the planned program, except two boys who had follow-ups after 12 instead of 18 months. The age of inclusion was 3 months to 4 years, the median age 17 months of age, and the median age for resection 3 months (Table 1). Ten patients were included directly after resection: seven patients were included median 24 months after resection (range 8 - 36 months). Children aged $0-1$ year were breastfed during the observation, whereas the older boys had a light meal.

\subsection{Findings from the 4-Hour Voiding Observation}

\subsubsection{Bladder Volumes}

The voided volumes increased among the children with PUV according to age from the investigations at inclusion to the 18-month follow-up. The bladder volumes (highest voided volume plus residual urine left on that occasion) in the different age groups are shown in Table 2. The mean bladder volume in children aged $0-1$ year was $26 \mathrm{ml}$ (median $26 \mathrm{ml}$ ) at the first visit. At the 18-month investigations, the mean was $86 \mathrm{ml}$ (median 57 $\mathrm{ml}$ ). When comparing the boys with PUV with the healthy boys, the boys with PUV had lower bladder volumes than the healthy boys at age $0-1$ year $(\mathrm{p} \leq$ 0.001) (Table 3). When comparing the total urinary volumes during the 4 hours, there was no difference between the PUV group and the healthy group in the age groups $0-1$ and $1-2$ years, suggesting that the boys in the group with valves were not polyuric at this age. In the age group $2-4$ years, the urinary volumes were higher in the boys with PUV $(p=0.02)$.

\subsubsection{Number of Voidings}

The boys with PUV voided 3 - 5 times during the follow-up with a tendency of less frequent voids at the 18-month follow-up (Table 2).

In the comparisons of boys with PUV and healthy 
Table 3. Highest bladder volume triggering voiding and postvoid residual urine (PVR); a comparison between Vietnamese boys with PUV and healthy boys. In the healthy Vietnamese boys, only values up to the age of 3 years were available. The columns show Mean (SD), Median (min - max).

\begin{tabular}{|c|c|c|c|}
\hline \multirow[t]{3}{*}{ Age groups } & PUV & Healthy & \multirow{2}{*}{$\begin{array}{c}\text { Vietnamese } \\
\text { PUV vs. } \\
\text { Healthy } \\
\text { Vietnamese }\end{array}$} \\
\hline & & & \\
\hline & & & P-value \\
\hline & $\mathbf{n}=\mathbf{1 7}$ & $n=26$ & \\
\hline & $n$ & $n$ & \\
\hline 0 - 1 year & 8 & 26 & \\
\hline \multirow[t]{2}{*}{ Age (year) } & $0.5(0.1)$ & $0.5(0.02)$ & 0.04 \\
\hline & $0.5(0.4-0.8)$ & $0.5(0.5-0.5)$ & \\
\hline Highest bladder & $27(10)$ & $45(11)$ & $<0.001$ \\
\hline volume (ml) & $26(17-48)$ & $45(26-68)$ & \\
\hline Total urinary & $65(42)$ & $50(10)$ & 0.12 \\
\hline volume/4 hrs (ml) & $45(27-143)$ & $45(26-68)$ & \\
\hline \multirow[t]{2}{*}{ Average PVR (ml) } & $4(2)$ & $5(5)$ & 0.8 \\
\hline & $3(1-8)$ & $3(0-18)$ & \\
\hline \multirow[t]{2}{*}{ Lowest PVR (ml) } & $2(2)$ & $2(3)$ & 0.05 \\
\hline & $2(0-6)$ & $0(0-12)$ & \\
\hline 1 - 2 years & 12 & 26 & \\
\hline \multirow[t]{2}{*}{ Age (years) } & $1.5(0.2)$ & $1.4(0.2)$ & 0.01 \\
\hline & $1.6(1.0-2.0)$ & $1.5(1.0-1.6)$ & \\
\hline Highest bladder & $62(32)$ & $60(12)$ & 0.6 \\
\hline volume (ml) & $50(26-120)$ & $60(36-86)$ & \\
\hline Total urinary & $153(65)$ & $131(33)$ & 0.6 \\
\hline volume/4 hrs (ml) & $131(76-303)$ & $126(66-215)$ & \\
\hline \multirow[t]{2}{*}{ Average PVR (ml) } & $1(1)$ & $0(0)$ & $<0.001$ \\
\hline & $1(0-3)$ & $0(0-1)$ & \\
\hline \multirow[t]{2}{*}{ Lowest PVR (ml) } & $0(1)$ & $0(0)$ & 0.01 \\
\hline & $0(0-3)$ & $0(0-0)$ & \\
\hline 2 - 4 years & 12 & 23 & \\
\hline \multirow[t]{2}{*}{ Age (years) } & $3.1(0.6)$ & $3(0.3)$ & 0.2 \\
\hline & $3.4(2.0-4.0)$ & $3(2.0-3.0)$ & \\
\hline Highest bladder & $78(49)$ & $72(31)$ & 0.9 \\
\hline volume (ml) & $64(17-200)$ & $60(33-140)$ & \\
\hline Total urinary & $202(105)$ & $138(43)$ & 0.02 \\
\hline Volume/4 hrs (ml) & $187(48-450)$ & $133(80-254)$ & \\
\hline \multirow[t]{2}{*}{ Average PVR (ml) } & $2(2)$ & $0(0)$ & $<0.0001$ \\
\hline & $2(0-8)$ & $0(0-0)$ & \\
\hline \multirow[t]{2}{*}{ Lowest PVR (ml) } & $1(1)$ & $0(0)$ & 0.01 \\
\hline & $0(0-4)$ & $0(0-0)$ & \\
\hline
\end{tabular}

boys, the boys with PUV showed a higher number of voids (Figure 1). The differences were statistically significant for ages $1-2$ and 2 - 4 years.

\subsubsection{Interrupted Voidings}

One boy with PUV (12.5\%) in the age group 0 - 1 year and two boys $(18.2 \%)$ in the group $1-2$ years showed interrupted voids. This habit was not shown in any patient after that.

In the group of healthy boys, the percentage of interrupted voids showed an even lower occurrence, 7.7\% and $3.8 \%$ respectively (Figure 2 ).

\subsubsection{Post-Void Residual Urine}

At inclusion and at the 18-month follow-up, the amount of post-void residual urine was low in the boys with PUV. At inclusion, the boys of $0-1$ year had an average of $3 \mathrm{ml}$ residual urine, and at the age of $1-2$ and $2-4$

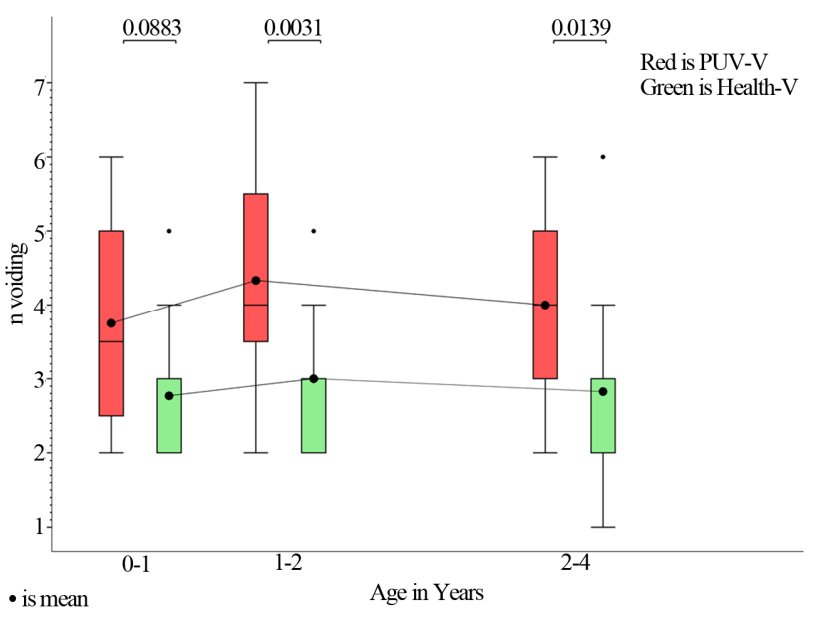

Figure 1. Number of voidings according to age in the Vietnamese group of boys with PUV compared with healthy Vietnamese boys.

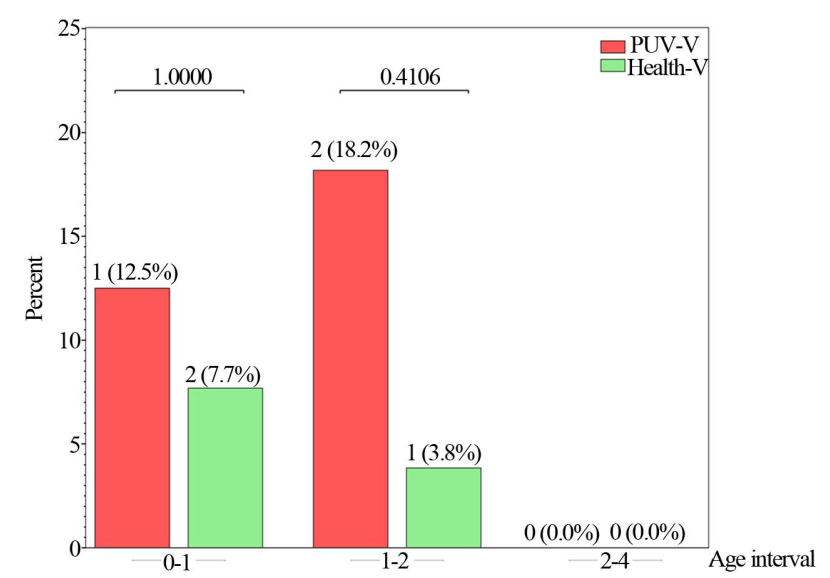

Figure 2. Percent of Vietnamese boys with PUV who presented interrupted voiding compared with healthy Vietnamese boys. 
years, 2 and $5 \mathrm{ml}$ respectively. These low values were even lower after the 18-month follow-up: average $2 \mathrm{ml}, 1$ $\mathrm{ml}$, and $1 \mathrm{ml}$, respectively (Table 2).

The healthy boys did not show any residual urine in the age groups after 1 year of age. In the comparison between boys with PUV and healthy boys, there was a significant difference in the groups $1-2$ and 2 - 4 years, even if the amount was also low in the group of boys with PUV (Table 3).

\section{DISCUSSION}

This pilot study is the first attempt to investigate if there are benefits of early potty training in a population with PUV. A recently published study comparing early pottytrained healthy Vietnamese children with healthy Swedish children concluded that potty training performed daily affected the emptying ability positively [13]. In the present study, Vietnamese boys with PUV, aged 3 months to 4 years, who were potty-trained according to the Vietnamese culture, were found to have few signs of bladder dysfunction, as judged from free voiding studies. However, when comparing the boys with PUV and healthy Vietnamese boys, a difference indicating abnormality in the bladder function of the boys with PUV could be seen. This was due to the finding in the PUV boys of smaller voided volumes at $0-1$ year, and a higher number of voidings and higher but still low number of interrupted voidings at ages 1 - 2 years compared with the healthy boys. These were signs that could be explained by the hypercontractile pattern of the bladders seen in young boys with PUV, induced by detrusor hypertrophy with concomitant detrusor overactivity. We do not know if the Vietnamese boys had detrusor overactivity since they were not investigated with invasive urodynamics. However, a previous study using 24 hours of natural fill cystometry in Swedish toddlers with PUV showed that boys with PUV had pronounced overactivity of the bladder in the daytime [14]. Higher residual urine after voiding was also seen after 1 year of age in the PUV boys in the present study, even if the absolute amount in milliliters was rather modest: the average highest was $8 \mathrm{ml}$.

It is a difficult task to perform randomized, controlled studies in boys with PUV, since the diagnosis comprises a great variety of secondary pathology to the urethral obstruction and different grades of primary renal dysplasia. In this study of 17 boys with PUV, half of the patients had dilated upper urinary tracts and only one third had dilated vesicoureteral reflux. The group also comprised boys with severe valves, as high creatinine levels were found, even if it was difficult to obtain the nadir values. In a previous Swedish study with 23 valve boys aged median 22 months and followed with the 4-hour voiding observation, more frequent voidings, more in- terrupted voidings, and higher post-void residual amounts were seen compared with this Vietnamese group of boys with PUV [15]. It could be argued that the Swedish group comprised more obstructive valves with the majority having dilated upper urinary tracts and half of them reflux. Furthermore, the culture and circumstances for the care of these patients differ between the countries and, thus, there may be dissimilarities. Nonetheless, the group of Vietnamese boys showed less pronounced symptoms of bladder dysfunction, suggesting that potty training from infancy could also have affected the bladders positively in the Vietnamese group.

Early potty training is a procedure that includes encouragement to start a micturition at 1 - 2-hour intervals in order to empty the bladder. This regular and frequent prompting from early infancy may induce the micturition reflex to be released voluntarily from the brain earlier than is the case of children who are potty-trained late, which may facilitate the development of good bladder habits. The Vietnamese children are held in a sitting position when urinating, and this may also be beneficial for complete emptying. This habit to practice starting a micturition by will has similarities with the recommended therapy used for older children with dysfunctional bladder disturbances, with the aim of calming down overactive bladders [16]. A study of girls by Wennergren has shown that the sitting micturition position facilitates relaxation of the pelvic floor muscles, which means improved emptying of the bladder [17]. Early potty training, as performed in the Vietnamese PUV boys, means earlier maturation of bladder function and can also be recognized in physiological bladder variables, such as emptying ability and interrupted voiding. Better emptying of the bladder at voiding, fewer interrupted voidings, and lower voided volumes have previously been shown in a study comparing healthy Vietnamese children who were potty-trained early with Swedish children who were trained late, as mentioned above [13]. The same pattern was seen for the Vietnamese boys with PUV regarding emptying ability and the number of interrupted voidings. Since we see interrupted voiding as a sign of physiological dyscoordination at voiding, the earlier disappearance of this phenomenon probably explains the early complete emptying.

Regarding bladder dysfunction and its change over time in boys with PUV, interest has focused on urinary volumes [18]. Polyuria is considered a determinant of the development of more severe dysfunction, which in turn leads to deterioration of renal function. In this study, only the PUV boys of 2 - 4 years had higher urinary volumes than the healthy boys during the 4-hour observation. Whether polyuria develops with age or the older group had more severe valves can only be speculated on. An argument against a more severe bladder dysfunction 
in the older boys was the fact that emptying improved at the 18-month follow-up compared with at inclusion. The improvement was probably related to the study design; they became aware of the emptying of their bladders.

This pilot study had a small number of patients and covered just one and a half years. We still need more research on this topic, and randomized long-term follow-up studies have to be conducted to evaluate if early potty training can counteract development of postnatal bladder dysfunction and be beneficial for the kidneys.

\section{CONCLUSION}

This study shows that the symptoms of bladder dysfunction were low in the Vietnamese boys with PUV who had been potty trained since infancy: there was no residual urine after the age of one, and interrupted voiding was rare as a sign that dyscoordination had disappeared. However, in comparisons, healthy Vietnamese boys had significantly fewer symptoms. The study indicates that early potty training with voiding at $1-2$ hour intervals during the time the child is awake may reduce symptoms from the urinary bladder, though whether this is, in fact, beneficial for the urinary bladder and the kidneys are not shown by this study.

\section{REFERENCES}

[1] Peters, C.A., et al. (1992) The effect of obstruction on the developing bladder. Journal of Urology, 148, 491-496.

[2] Parkhouse, H.F. and Woodhouse, C.R. (1990) Long-term status of patients with posterior urethral valves. Urologic Clinics of North America, 17, 373-378.

[3] Parkhouse, H.F., et al. (1988) Long-term outcome of boys with posterior urethral valves. British Journal of Urology, 62, 59-62. http://dx.doi.org/10.1111/j.1464-410X.1988.tb04267.x

[4] Taskinen, S., Heikkila, J. and Rintala, R. (2012) Effects of posterior urethral valves on long-term bladder and sexual function. Nature Reviews Urology, 9, 699-706. http://dx.doi.org/10.1038/nrurol.2012.196

[5] Peters, C.A., et al. (1990) The urodynamic consequences of posterior urethral valves. Journal of Urology, 144, 122126.

[6] Holmdahl, G., et al. (1995) The changing urodynamic pattern in valve bladders during infancy. Journal of Urology, 153, 463-467. http://dx.doi.org/10.1097/00005392-199502000-00058

[7] Jansson, U.B., et al. (2005) Voiding pattern and acquisition of bladder control from birth to age 6 years-A lon- gitudinal study. Journal of Urology, 174, 289-293. http://dx.doi.org/10.1097/01.ju.0000161216.45653.e3

[8] Duong, T.H., et al. (2010) Development of bladder control in the first year of life in children who are potty trained early. Journal of Pediatric Urology, 6, 501-505. http://dx.doi.org/10.1016/j.jpurol.2009.11.002

[9] Duong, T.H., Jansson, U.B. and Hellstrom, A.L. (2012) Vietnamese mothers' experiences with potty training procedure for children from birth to 2 years of age. Journal of Pediatric Urology. http://dx.doi.org/10.1016/j.jpurol.2012.10.023

[10] Sillen, U. (1999) Bladder dysfunction in children with vesico-ureteric reflux. Acta Paediatrica. Supplement, 88, 40-47. http://dx.doi.org/10.1111/j.1651-2227.1999.tb01317.x

[11] Jansson, U.B., et al. (2000) Voiding pattern in healthy children 0 to 3 years old: A longitudinal study. Journal of Urology, 164, 2050-2054. http://dx.doi.org/10.1016/S0022-5347(05)66963-7

[12] Holmdahl, G., et al. (1996) Four-hour voiding observation in healthy infants. Journal of Urology, 156, 18091812. http://dx.doi.org/10.1016/S0022-5347(01)65543-5

[13] Duong, T.H., et al. (2013) Urinary bladder control during the first 3 years of life in healthy children in Vietnam-A comparison study with Swedish children. Journal of Pediatric Urology. http://dx.doi.org/10.1016/j.jpurol.2013.04.022

[14] Holmdahl, G., et al. (1997) Natural filling cystometry in small boys with posterior urethral valves: Unstable valve bladders become stable during sleep. Journal of Urology, 158, 1017-1021. http://dx.doi.org/10.1016/S0022-5347(01)64378-7

[15] Holmdahl, G., et al. (1998) Four-hour voiding observation in young boys with posterior urethral valves. Journal of Urology, 160, 1477-1481. http://dx.doi.org/10.1016/S0022-5347(01)62596-5

[16] Neveus, T., et al. (2006) The standardization of terminology of lower urinary tract function in children and adolescents: Report from the Standardisation Committee of the International Children's Continence Society. Journal of Urology, 176, 314-324. http://dx.doi.org/10.1016/S0022-5347(06)00305-3

[17] Wennergren, H.M., Oberg, B.E. and Sandstedt, P. (1991) The importance of leg support for relaxation of the pelvic floor muscles. A surface electromyograph study in healthy girls. Scandinavian Journal of Urology and Nephrology, 25, 205-213. http://dx.doi.org/10.3109/00365599109107948

[18] Koff, S.A. and Murtagh, D. (1984) The uninhibited bladder in children: Effect of treatment on vesicoureteral reflux resolution. Contributions to Nephrology, 39, 211-220. 